\title{
Avaliação das potencialidades de um curso prático de bioquímica como ferramenta auxiliar ao ensino teórico em cursos profissionalizantes
}

Autores:Regis, Wiliam C.B.(1); Gonçalves, Maria Lúcia G.S.(2) Santoro, Marcelo M.(3) Afiliação:(1)Grupo Biofísica Molecular, Centro de Biologia Molecular Estrutural-LNLS. (2)BIOBRÁS-SA (3) Laboratório de Enzimologia e Físico-Química de Proteínas, ICB, UFMG.

wregis@Inls.br

What we can observe currently about professional formation is the pure and simple fixation of protocols and procedures in a sequential and mechanical way. These procedures deny the students the knowledge of theoretical principles involved in the techniques used in their professional works. In this work we evaluate the idea of implementing small biochemistry modules in technical education in order to assist the formation of professionals with better capacity to take decisions. For such, a good theoretical knowledge is the base of the practical procedures to give the students enough security and independence to manipulate the techniques in their works. The model evaluated here, a practical course of purification and analysis of proteins that is offered to the whole community, was carried out in the Laboratory of Enzimology and Physico-Chemistry of Proteins of the Department of Biochemistry and Immunology, of the Institute of Biological Sciences of the Federal University of Minas Gerais. We have noticed that some constructivist features of this course indicates it as a good instrument for the enrichment of the proffesionnal formation of our students.

\section{RESUMO}

O que se pode observar atualmente sobre a formação profissionalizante é a pura e simples fixação de protocolos e procedimentos de forma mecânica e seqüencial, o que renega ao estudante o conhecimento dos princípios teóricos que determinam os procedimentos de sua profissão. Este trabalho procura avaliar a tentativa de implantar pequenos módulos práticos de bioquímica no ensino técnico para auxiliar na formação de profissionais com maior capacidade de tomar decisões. Para tal, pressupõe-se ser fundamental uma boa implementação teórica a respeito das práticas executadas, para que realmente se possibilite ao estudante segurança e independência suficientes para manipular as técnicas por eles executadas em suas carreiras profissionais. O modelo aqui avaliado foi o Curso prático de Purificação e Análise de Proteínas realizado no Laboratório de Enzimologia e Físico-Química de Proteínas do Departamento de Bioquímica e Imunologia, através da extensão do Instituto de Ciências Biológicas da Universidade Federal de Minas Gerais. Foram encontradas várias características construtivistas na prática executada indicando-o como um bom instrumento para o enriquecimento da formação técnica em nosso país.

\section{I NTRODUÇÃO}

Para que um ambiente de ensino seja construtivista, é fundamental que o professor conceba o conhecimento sob a óptica levantada por Piaget, ou seja, que todo e qualquer desenvolvimento cognitivo só será efetivo se for baseado em uma interação muito forte entre o sujeito e o objeto. É imprescindível que se compreenda que, sem uma atitude do objeto que perturbe as estruturas do sujeito, este não tentará acomodar-se à situação, criando uma futura assimilação do objeto, dando origem às sucessivas adaptações do sujeito ao meio, com o constante desenvolvimento de seu cognitivismo. 
Desta forma, apesar de acreditar ser perfeitamente possível a utilização de um "ambiente empirista" por um professor que não veja o aluno como "tabula rasa" para o desenvolvimento de um conhecimento, na forma como Piaget teorizou, existem alguns pressupostos básicos de sua teoria que devem ser levados em conta, se desejarmos criar um "ambiente construtivista". A primeira das exigências é que o ambiente permita, e até obrigue, uma interação muito grande do aprendiz com o objeto de estudo. Esta interação, contudo, não significa apenas o apertar de teclas ou o escolher entre opções da tela de um aparelho. Esta prática deve ser conduzida de forma a estimulá-lo e desafiá-lo, mas ao mesmo tempo permitindo que as novas situações criadas possam ser adaptadas às estruturas cognitivas existentes, propiciando o seu desenvolvimento. Para tal, a interação deve abranger preferencialmente aluno - aluno e aluno - professor através da troca de suas experiências pregressas e de novos problemas.

Outro aspecto primordial nas teorias construtivistas é a quebra de paradigmas que os conceitos de Piaget trazem; é a troca do repasse da informação para a busca da formação do aluno; é a nova ordem revolucionária que retira o poder e autoridade do mestre transformando-o de todo poderoso detentor do saber para um "educador - educando", segundo as palavras de Paulo Freire. Esta visão deve permear todo um "ambiente construtivista". Rogers complementa que, mais do que repassar conhecimentos, a função de um professor que se propõe a ser facilitador seria "liberar a curiosidade; permitir que os indivíduos arremetam em novas direções ditadas pelos seus próprios interesses; tirar o freio do sentido de indagação; abrir tudo ao questionamento e à exploração; reconhecer que tudo se acha em processo de mudança..."

Becker afirma que "se é esquisito dizer que um método é construtivista, dizer que um currículo é construtivista é mais esquisito ainda." Isto posto, não seria também ridículo falar-se em um "ambiente construtivista"? Ou ainda, qual o resultado que será obtido por um professor cuja concepção do conhecimento for empirista ao utilizar um "ambiente construtivista" ou sua recíproca, o resultado da utilização de um "ambiente empirista" por um professor com uma epistemologia do conhecimento baseada nas teses construtivistas? Esse pode ser um dos principais desafios das instituições de ensino que visam a formação técnica.

O que se pode observar atualmente sobre a formação profissionalizante é a pura e simples fixação de protocolos e procedimentos de forma mecânica e seqüencial, o que renega ao estudante o conhecimento dos princípios teóricos que determinam os procedimentos de sua profissão.

Este trabalho procura avaliar a tentativa de implantar pequenos módulos práticos de bioquímica no ensino técnico para auxiliar na formação de profissionais com maior capacidade de tomar decisões. Para tal, pressupõe-se ser fundamental uma boa implementação teórica a respeito das práticas executadas para que realmente se possibilite ao estudante segurança e independência suficientes para manipular as técnicas por eles executadas em suas carreiras profissionais.

Para fazer tal avaliação, o modelo aqui estudado será um curso prático de técnicas bioquímicas implantado na extensão da Universidade Federal de Minas Gerais, no qual foram encontradas várias características construtivistas indicando-o como um bom exemplo no auxílio à formação técnica.

\section{DESCRI ÇÃO DO CURSO}

\subsection{Histórico do curso:}

Outubro de 1998: Projeto Piloto na XI Semana de Estudos de Biologia

Novembro de 1998: Encaminhamento do projeto de Extensão

Dezembro de 1998: Aprovação pela Pró-Reitoria de Extensão

Junho de 1999: I Curso Prático de Purificação e Análise de Proteínas

Janeiro de 2000: II Curso Prático de Purificação e Análise de Proteínas

\section{ANÁLI SE DAS PRI NCI PAIS ETAPAS DO CURSO}




\subsection{Extração e Tratamento de Material Biológico}

No curso piloto e no primeiro curso pela extensão foi utilizada a hemolinfa de $\underline{B}$. glabrata como extrato primário. Ela é extraída por punção cardíaca e colocada imediatamente na presença de inibidores de proteases (EDTA , E-64 , 3,4-DCl, Pepstatina-A), então centrifugada por 10 minutos numa microcentrífuga, Eppendorf Modelo 5415C, a 10.000 r.p.m.

A descrição pura e simples do protocolo como citado acima é usualmente encontrada em artigos de referência sobre o assunto. No curso, nós promovemos a aproximação do aluno com o material, fazendo com que cada um deles realizasse a punção cardíaca no molusco, tendo assim maior interação com a dimensão do processo que envolve as etapas inicias de purificação de proteínas. À medida em que eles iam executando a prática, os detalhes sobre os inibidores, os motivos de utilização de cada classe dos mesmos e as concentrações usadas eram explicitados e problemas nesta etapa eram discutidos. Os erros experimentais eram muitos e com isto eles foram tomando consciência do processo com suas implicações práticas que, na maioria das vezes, parece distante da teoria mencionada.

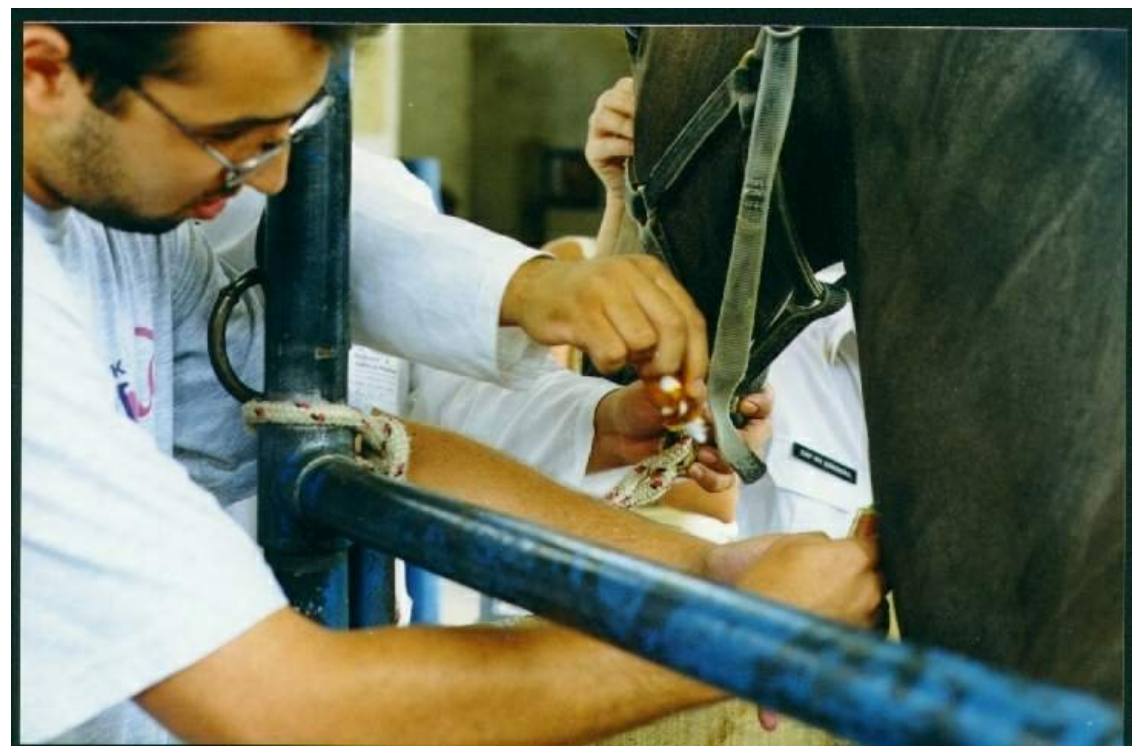

Figura 1. Extração do material biológico a ser utilizado pelos alunos do II Curso.

Os alunos demonstraram uma grande satisfação ao realizar esta prática, principalmente após a aula teórica que tinha causado uma certa apreensão nos alunos do projeto piloto, o que pode ser constatado nos questionários de avaliação final do curso. Esta negativa à aula teórica e comentários do tipo "Agora estou entendendo o que você estava falando..." reforça a idéia de que um problema proposto através de uma atividade prática, quando bem conduzida, estimula o raciocínio do aluno em cima da teoria relacionada ao tema.

\subsection{Diálise}

Esta é uma técnica muito utilizada em bioquímica quando se quer alterar os solventes de uma solução ou simplesmente as concentrações da mesma. Como toda a estrutura do curso é prática, mais uma vez os alunos executavam os procedimentos e, nesta etapa, fizemos a pratica também com um corante para que todos pudessem visualizar os princípios bioquímicos da técnica. Foi preparada uma solução com um corante bem concentrado e que passaria facilmente pela membrana de diálise escolhida. Após um determinado período de tempo, ao ser colocada em um recipiente com água, a solução interna da membrana ia perdendo coloração demonstrando a passagem do corante para o lado de fora da membrana. 


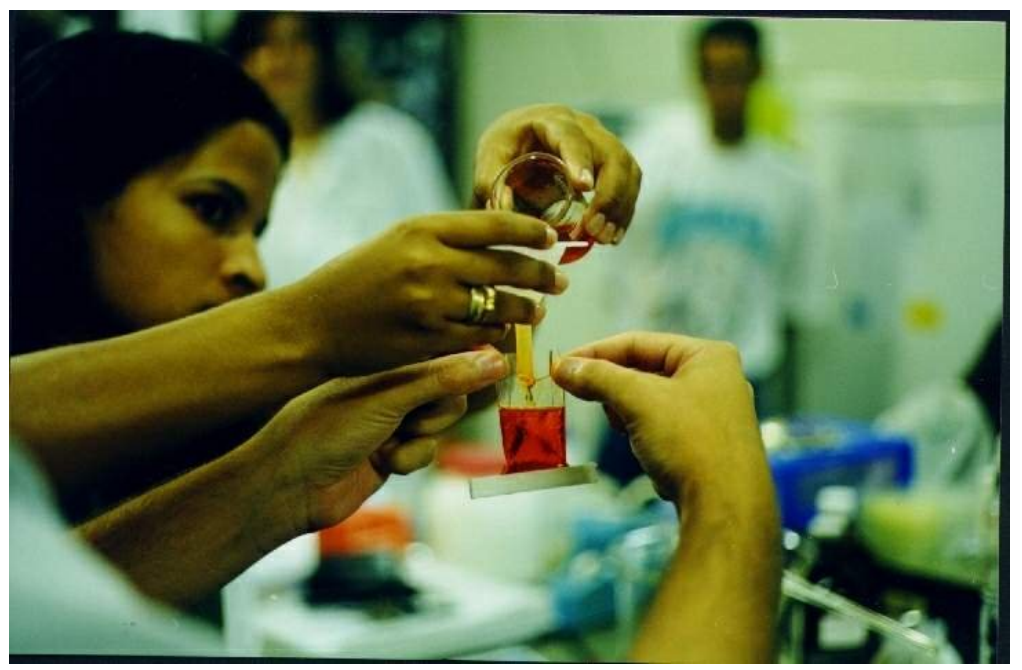

Figura 2. Alunos montando sistema para dialisar um corante contra água

Este é um bom modelo que se pode utilizar ao passar conceitos como difusão e osmose. Observamos, através das conversas entre eles, que o fato deles próprios manipularem o corante, escolherem a membrana correta e montarem o sistema gera um maior envolvimento e uma maior elaboração do conceito. Quando o princípio teórico tem de ser verbalizado, para comunicação entre os colegas, os raciocínios sobre os mesmos tornam-se mais coerentes e elucidativos para os próprios alunos. A prática, sob esta abordagem, tem um papel fundamental.

\subsection{Cromatografia de Gel Filtração}

A cromatografia de Gel Filtração apresentou peculiaridades em cada curso e sofreu modificações em função do observado pelos professores.

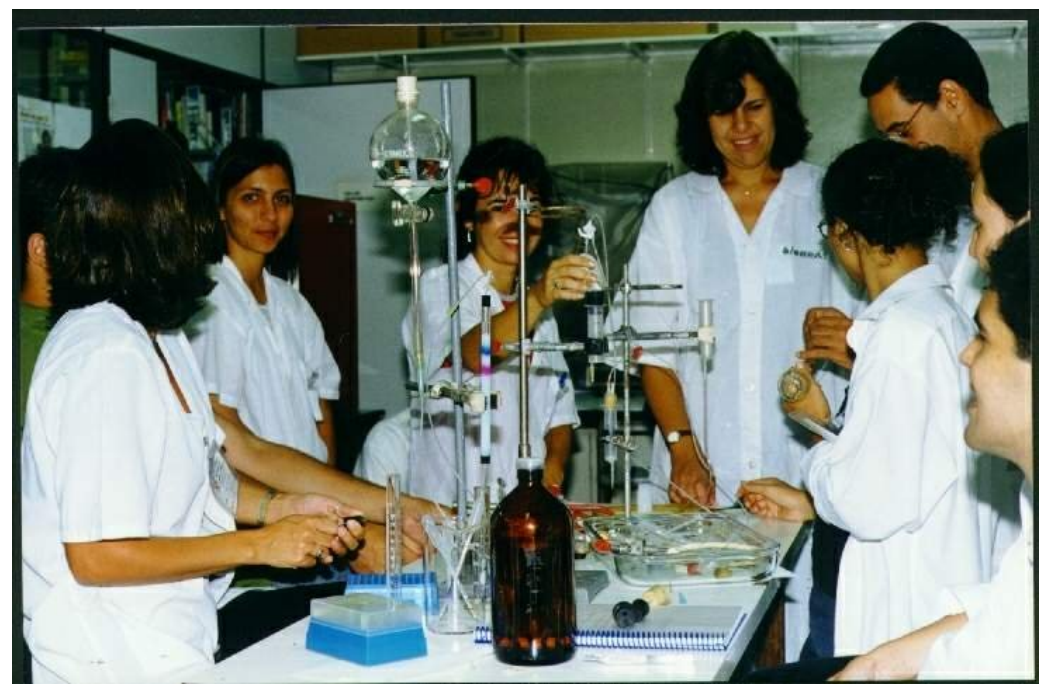

Figura 3. Cromatografia de Gel Filtração utilizando-se de colunas montadas pelos próprios alunos do curso

No projeto piloto o nível de aula, considerando apenas o aprofundamento que deveria ser dado, foi bem menor do que se esperava. Os alunos apresentavam dúvidas básicas que não eram esperadas considerando que já haviam cursado a disciplina de bioquímica e tinham tido uma aula teórica introdutória no curso. A manifestação dos alunos de ter entendido os conceitos apenas diante do aparelho levou a retirada da aula teórica do curso deixando-o com um caráter essencialmente prático.

No primeiro curso pela extensão, ainda utilizando a hemolinfa do molusco, a técnica pôde ser melhor compreendida devido à visualização da proteína no sistema. As explicações diante do aparelho foram fundamentadas nas dúvidas apresentadas pelos alunos do projeto piloto. Isto fez com que a prática se desenvolvesse com mais tranqüilidade. Uma outra modificação nesta etapa do curso foi o desenvolvimento da 
técnica sem o aparelho. Foi demonstrado aos alunos como montar, com baixo custo, um sistema para purificação em bancada. Esta prática envolveu a montagem do sistema completo, o que possibilitou o aprendizado mais elaborado em conseqüência de maiores discussões sobre a técnica. Este assunto tem a peculiaridade de possuir como um determinante fortíssimo de sua teoria os pequenos detalhes instrumentais. Variações, por exemplo, em fluxo e tamanho da coluna, podem falsificar resultados, levando a uma extrapolação indevida dos dados obtidos pela técnica. Os alunos tiveram a possibilidade de "brincar" com essas variáveis e fixar melhor os conceitos hidrodinâmicos que as determinam. Com isto, eles ganharam uma melhor assimilação das teorias e dos princípios físicos gerais que determinam a sua prática profissional.

No segundo curso, além das modificações anteriores, foi acrescentado um tempo maior no manuseio do aparelho pois não seria de todo útil passar apenas como se liga e quais os botões devem ser apertados. Os alunos propunham condições experimentais e criavam métodos no aparelho para a execução dos mesmos. Este exercício é fundamental para o desenvolvimento do profissional na área bioquímica porque o leva ao treinamento na tomada de decisões, fazendo com que ele não só fixe o princípio bioquímico, mas possa trabalhá-lo de forma a aperfeiçoar o desempenho dos seus métodos. Desta maneira, a teoria foi invadindo o cotidiano instrumental do aluno e deixou de ser, como para muitos, uma desconhecida, passando a ser uma aliada e uma âncora da segurança profissional de cada um, isto pôde ser evidenciado quando os alunos responderam que são capazes de reconhecer e escolher as técnicas de purificação.

\subsection{Dosagem espectrofotométrica da Hemoglobina}

Esta técnica foi também muito conturbada no projeto piloto devido ao grande número de dúvidas. O procedimento adotado, uma vez que a explicação do aparelho não leva muito tempo, foi o uso de exercícios para cálculo de concentrações protéicas através dos resultados obtidos pelos próprios alunos. Este procedimento causou grande satisfação e interesse nos alunos, pois retrata fielmente os desafios que eles encontram no seu dia a dia como profissionais ligados à área bioquímica. O mais curioso desta técnica e o que a faz relatar tão claramente os problemas cotidianos da bioquímica é que ela se apropria ao mesmo tempo de conceitos de Física, Matemática e Química. É desfeita na cabeça dos alunos, principalmente dos que escolhem profissões de nível técnico ou superior na área biológica, a idéia do conhecimento específico e isolado de cada área, mostrando como as teorias, às vezes tão odiadas, são amplamente utilizadas em biologia e exercem um papel fundamental no seu desenvolvimento.

\subsection{Eletroforese}

No projeto piloto e no primeiro curso da extensão, a eletroforese foi feita no estilo "Mais Você", apresentando um sistema a ser montado pelos alunos e outro já montado. Isto foi necessário devido à maior complexidade experimental da técnica. Apesar da prática não ser das mais ideais, por apresentar etapas já prontas, vários princípios foram abordados e discutidos amplamente durante as atividades.

Nos cursos seguintes poucas adaptações foram feitas, porém as discussões foram bastante amplas e diversas modalidades da técnica foram discutidas.

\section{AVALI AÇÃO DOS RESULTADOS E DISCUSSÃO}

Ao final de cada curso foi aplicado um questionário de avaliação que teve como intuito inicial apenas colher informações sobre o impacto do curso. A última pergunta desse questionário, porém, levantava uma questão prática: um problema que visava a purificação de alguma substância. O que queríamos dessas respostas era ter uma idéia geral dos conceitos que foram mais bem fixados. Com essas respostas poderíamos também identificar as falhas do curso, caso alguma etapa importante fosse desconsiderada ou mal utilizada. Devido a uma grande parte das respostas terem sido redigidas sob forma de esquema, a avaliação tornou-se pouco conclusiva quanto à verificação de como um conteúdo prático pode auxiliar na fixação de conceitos teóricos. Há, porém, perguntas que nos levam a esses indícios como, por exemplo, uma questão na qual perguntamos diretamente sobre a implementação de conceitos teóricos suficientes ao conteúdo prático do curso. Uma outra questão visava avaliar a segurança dos alunos diante do conteúdo; perguntávamos a eles se sentiam capazes, após o curso, de escolher e reconhecer as técnicas utilizadas em etapas de isolamento de macromoléculas. Podemos, então, agrupar as respostas ao problema formulado da seguinte forma:

1) as que se limitaram a citar as técnicas do curso numa ordem já conhecida. Este grupo de resposta indicaria 
uma insegurança maior quanto ao conteúdo.

2) as que descrevem esquematicamente etapas coerentes e não necessariamente fiéis às vistas no programa. Este grupo de resposta indicaria uma maior capacidade de elaboração dos conceitos, evidenciando um acréscimo na estruturação da teoria pelo indivíduo.

3) respostas que indicaram um esquema de purificação e explicitaram os princípios teóricos gerais de cada etapa, demonstrando uma estratégia bem clara. Este tipo de resposta seria a mais indicada para atestar claramente a eficiência do curso no seu propósito. Porém, a pergunta não deixa clara esta necessidade de explicitação teórica das etapas.

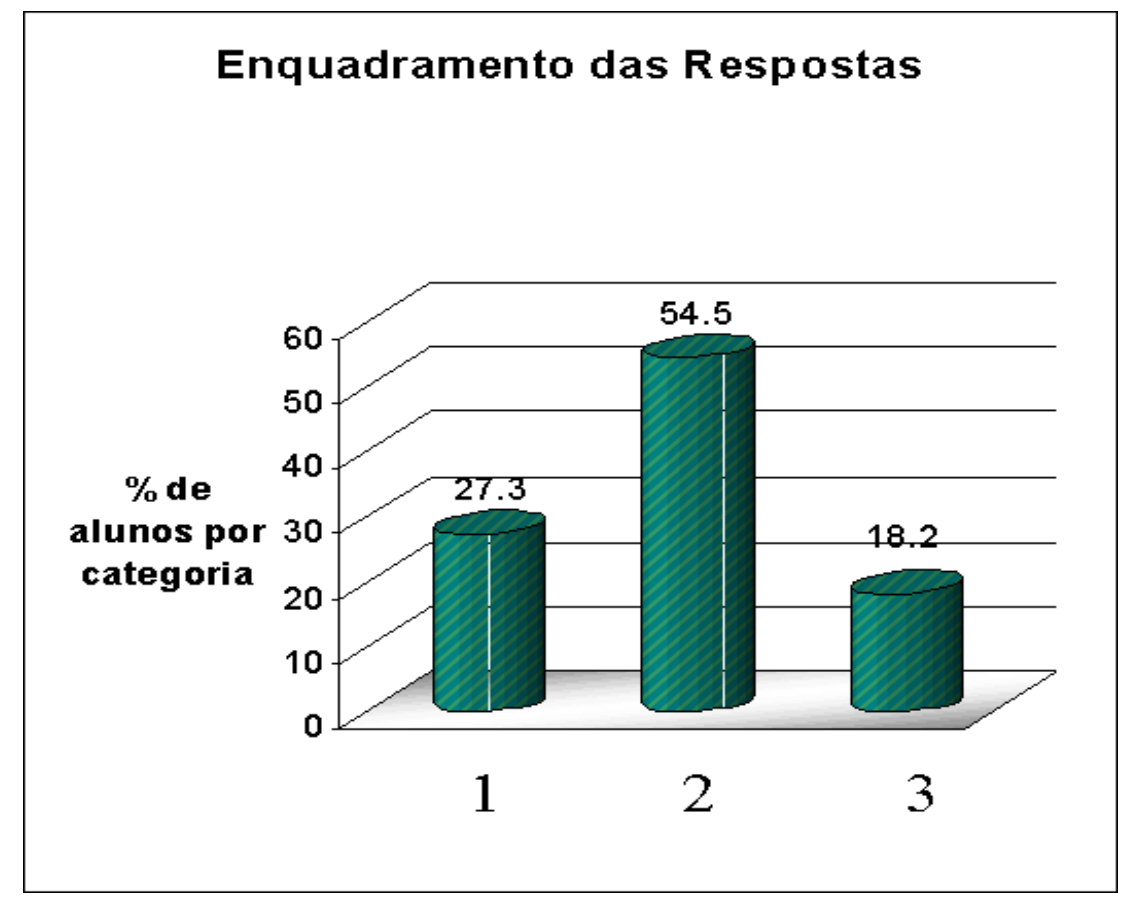

Gráfico 1. Percentual de alunos em cada agrupamento proposto.

Esses dados nos mostram um possível indício de que os conceitos foram fixados considerando que os alunos eram questionados sobre suas dúvidas o tempo inteiro pelos ministrantes. Este é um fator de extrema relevância, uma vez que o ambiente proporcionado era bastante pessoal e os alunos se sentiram bastante à vontade com os professores para sanar qualquer dúvida que ficasse pendente em cada parte experimental executada.

Os professores, neste curso, deixaram de ocupar um lugar central no desenvolvimento da prática, passando a atuar como orientadores e parceiros dos alunos que puderam dialogar sob suas próprias perspectivas como pressupôs FINEMANN e BOOTZ (1995).

No curso os alunos foram considerados como indivíduos ativos na construção do seu próprio conhecimento, uma vez que sempre eram estimulados a utilizar os conhecimentos anteriores, de suas diversificadas formações, para enfrentar as novas situações propostas pelo curso. As opiniões dos alunos, mesmo que por "simples bom senso", eram trabalhadas na forma de discussões em grupo sobre as práticas, como é considerado por STEFFE e GALLE (1995).

Inúmeras ações descritas por BROOKS e BROOKS (1995) a respeito do comportamento do professor puderam ser encontradas na nossa prática pela extensão da UFMG como, por exemplo: o questionamento sobre a compreensão do estudante antes de dividir seus próprios conceitos sobre o tema, prática esta que permeou todos os módulos; o estímulo aos estudantes para que eles dialogassem com o professor e entre si; o encorajamento dos mesmos resolverem problemas abertos e perguntarem uns aos outros sobre o tema, durante a condução das práticas e, principalmente, na discussão dos resultados; e o estímulo para que os estudantes assumissem as responsabilidades e conduzissem as práticas. 
Avaliar a prática de forma mais ampla, como um projeto pedagógico que pretenda possuir bases construtivistas é difícil, pois a estrutura do curso não nos permite isso. O que nos levou à avaliação de suas características construtivistas foi apenas a intenção de colocá-lo como um complemento à teoria relacionada às práticas executadas no ensino médio com o direcionamento para a formação técnica.

\section{CONCLUSÕES}

De uma forma geral, refletindo sobre o Curso Prático de Purificação e Análise de Proteínas, podemos indicar que esse se apresentou como uma boa iniciativa para o uso no complemento do ensino técnico através de módulos, pois nele puderam ser observados vários elementos da prática construtivista, de acordo com os modelos de BROOKS E BROOKS (apud NCREL, 1995), STEFFE e GALLE (apud BENAIM, 1995) e FINEMANN e BOOTZ (1995) acima descritos, modelos estes que propõem uma formação mais sólida do indivíduo e que desejamos observar em nossos técnicos.

\section{BI BLI OGRAFI A}

BECKER, F, O que é Construtivismo?, Revista de Educação AEC, Ano 21,№23, Abril/J unho de 1992.

BENAIM, D. Memorandum for Dalton School's Educational Policy Committee. nov. 1995

BROOKS, J.G., \& BROOKS, M.G. (1993). In search of understanding: The case for constructivist classrooms. Alexandria, VA: Association for Supervision and Curriculum Development.

FINEMANN, E. e BOOTZ, S. An introduction to constructivism in Instructional Design. 1995 Technology and Teacher Education Annual. University of Texas, Austin. 1995.

NCREL. North Central Regional Educational Laboratory (1997) Pathways to school improvement.

PIAGET, J, O Nascimento da Inteligência na Criança, 4a edição, Rio de Janeiro, Zahar, 1982

RIBEIRO, J.G. C. G., O ambiente como elemento facilitador da reflexão pedagógica sobre a prática educativa.

ROGERS, C.R., Liberdade para aprender em nossa década, Artes Médicas, 1985.

http://www.ncrel.org/sdrs/areas/issues/content/cntareas/science/sc5model.htm 